\title{
DESEMPENHO DO BRASIL NAS EXPORTAÇÕES DE MADEIRA SERRADA ${ }^{1}$
}

\author{
Rommel Noce², Rosa Maria Miranda Armond Carvalho ${ }^{3}$, Thelma Shirlen Soares ${ }^{3}$ e Márcio Lopes da Silva ${ }^{4}$
}

RESUMO - Com este trabalho objetivou-se verificar a competitividade dos principais exportadores de madeira serrada, por meio da decomposição das variações nas exportações de madeira no período de 1997 a 1999. Foram analisados Brasil, Canadá, Estados Unidos, Finlândia e Suécia pelo modelo Constant Market Share. A aplicação de tal modelo possibilitou constatar que o aumento das exportações brasileiras no período se deve a fatores endógenos, ao contrário do que foi observado em relação às outras nações.

Palavras-chave: Constant Market Share e exportações de madeira.

\section{BRAZILIAN PERFOMANCE IN SAWN TIMBER EXPORT}

\begin{abstract}
This work analyzed Brazilian saw timber competitiveness in the international market studying the export variations from 1997 to 1999. Brazil, Canada, USA, Finland and Sweden were analyzed by using the constant-market-share analysis. The analyses showed that the Brazilian export increase during that period is dependent on endogenous factors, contrary to what was observed in the other nations.
\end{abstract}

Key words: constant-market-share and timber exports.

\section{INTRODUÇÃO}

Atualmente, pode-se observar o surgimento de um consenso sobre a importância representativa que os recursos florestais assumem no âmbito da economia de países em desenvolvimento, uma vez que eles são uma alternativa viável para superar as dificuldades socioeconômicas através de sua diversidade e abundância e da gama de produtos que podem ser obtidos, direta e indiretamente, da floresta.

De acordo com o BNDES (2000), o consumo mundial de produtos florestais apresentou, nos últimos anos, taxas médias de crescimento em torno de 1,5\% a.a. Dados estatísticos indicam que as exportações brasileiras de produtos florestais têm crescido significativamente, devendo-se ressaltar que o Brasil já se mostra expressivo no comércio internacional de compensados tropicais, chapas de fibra, celulose de eucalipto e de papéis para imprimir e escrever.

Além do avanço de mercado, deve ser destacada a ocorrência de valorização do preço dos produtos florestais, o movimento de agregação de valor, o reflexo de políticas governamentais adotadas em resposta às crescentes pressões de ambientalistas, principalmente contra o corte das florestas tropicais.

Além do avanço de mercado, deve ser destacada a ocorrência de valorização do preço dos produtos florestais, além do movimento de agregação de valor, reflexo de políticas governamentais adotadas em resposta às crescentes pressões de ambientalistas, principalmente contra o corte das florestas tropicais.

Sendo assim, as perspectivas desse negócio nos mercados interno e externo apresentam-se promissoras,

1 Recebido para publicação em 14.11.2002.

Aceito para publicação em 9.9.2003.

2 Administrador de Empresas, Especialista em Gestão e Manejo Ambiental na Agroindústria, RNoce Consultoria, $36570-000$ Viçosa-MG. ${ }^{3}$ Doutoranda em Ciência Florestal na Universidade Federal de Viçosa - UFV, 36570-000 Viçosa-MG; ${ }^{4}$ Professor do Departamento de Engenharia Florestal da UFV. 
principalmente para aqueles produtos que incorporem tecnologia mais avançada aliada à qualidade, tanto da madeira quanto do processamento.

Angelo et al. (1998) relatam que a importância estratégica dos recursos naturais na produção de madeira serrada oferece ao Brasil a oportunidade de aumentar sua participação no comércio mundial. Assim, desenvolveu-se este estudo com o objetivo de avaliar o desempenho do setor florestal brasileiro de madeira serrada no mercado internacional, buscando correlacionar o aumento das exportações a fatores causais endógenos ou exógenos.

\section{MATERIAL E MÉTODOS}

A fim de analisar a competitividade do setor brasileiro de madeira serrada no mercado internacional, fezse, inicialmente, uma análise descritiva da variação de participação dos principais importadores e exportadores de madeira serrada.

Devido à não-disponibilidade de dados para grandes séries temporais, a análise foi realizada ao comparar os anos de 1997 e 1999, utilizando a base de dados disponibilizada pela Food and Agriculture Organization of the United Nations (FAO, 2002).

O mercado foi definido como uma lista de 15 países: Alemanha, Austrália, Bélgica, Canadá, China, Dinamarca, Espanha, Estados Unidos, França, Irlanda, Itália, Japão, Países Baixos, Reino Unido ${ }^{1 /}$ e Tailândia. Tais países, além de comercializarem com os países analisados, representam cerca de $80 \%$ da importação mundial de madeira serrada. Os demais importadores foram agrupados como Resto do Mundo.

Inicialmente, fez-se uma análise descritiva da variação de participação dos principais importadores e exportadores de madeira serrada, analisando a exportação dos cinco países que respondem por mais da metade da madeira serrada exportada mundialmente: Canadá, Suécia, Finlândia, Estados Unidos e Brasil.

Neste estudo, entendeu-se competitividade como o desempenho dos países nas exportações, tendo sido consideradas competitivas as nações que ampliam sua participação no comércio mundial de determinados produtos, conforme estudos realizados por Gonçalves (1987), Horta (1993), Medeiros \& Fontes (1994) e Angelo et al. (2000).

\footnotetext{
1/ A Irlanda não é apresentada com valor agregado ao Reino Unido e o valor de suas importações é considerado como um mercado distinto.
}

O desempenho das exportações foi verificado através da decomposição da variação efetiva das exportações de um determinado bem em efeito conjuntura internacional (taxa de crescimento do comércio mundial), efeito produto (evolução das transações internacionais do produto) e efeito mercado (evolução das importações dos países de destino).

Para decompor a variação nas exportações de madeira serrada dos exportadores considerados, utilizou-se uma simplificação do modelo Constant Market Share desenvolvido por Richardson (1971), o que permitiu avaliar a contribuição de cada um dos componentes para o aumento ou decréscimo das exportações, através da seguinte função matemática:

$\sum\left(V^{\prime}{ }_{j}-V_{j}\right)=r V_{j}+\sum\left(r_{j}-r\right) V_{j}+\sum\left(V_{j}^{\prime}-V_{j}-r_{j} V_{j}\right)$

em que $V_{j}=$ valor das exportações de madeira serrada do país em questão para o mercado $j$, no período 1 (1997); $V_{j}^{\prime}=$ valor das exportações de madeira serrada do país em questão para o mercado $j$, no período 2 (1999); $V_{j}^{\prime}-$ $V_{j}=$ crescimento efetivo do valor das exportações de celulose do país em questão para o mercado $j ; r j=\left[\left(X m^{\prime} j\right)\right.$ $X m j)-1]=$ taxa de crescimento porcentual do valor das exportações mundiais de madeira serrada para o mercado $j ; r=\left[\left(X m^{\prime} / X m\right)-1\right]=$ taxa de crescimento porcentual do valor das exportações mundiais de madeira serrada; $X m_{j}=$ valor das exportações mundiais para o mercado $j$, exceto as exportações do país em questão, no período 1 (1997); e X $m_{j}{ }_{j}=$ valor das exportações mundiais para o mercado j, exceto as exportações do país em questão, no período 2 (1999).

De forma que os efeitos são determinados por:

$\sum_{j=1}^{n} r V_{j}=$ efeito crescimento

$\sum_{j=1}^{n} r_{j} V_{j}-\sum_{j=1}^{n} r V_{j}=$ efeito destino

(3); e

$\sum_{j=1}^{n} V^{\prime}{ }_{j}-\sum_{j=1}^{n} V_{j}-\sum_{j=1}^{n} r_{j} V_{j}=$ efeito competitividade (4);

O modelo propõe que:

- o efeito crescimento do comércio mundial de madeira serrada representa o crescimento porcentual, ou decréscimo, que seria observado caso as exportações do país crescessem proporcionalmente ao comércio mundial; 
- o efeito destino representa os ganhos e as perdas em função de as exportações serem direcionadas a países que cresceram a taxas superiores ou inferiores à média do mercado mundial; e

- o efeito contribuição representa os ganhos e as perdas em participação no mercado de cada país em função da competitividade do produto, podendo ser em preço, custo ou qualidade.

Os efeitos de crescimento e destino são exógenos, pois representam a expansão e o aquecimento dos mercados-alvo, respectivamente, sendo fatores externos às nações. Já o efeito contribuição ou competitividade é endógeno, determinado por fatores internos às nações como competitividade em custo, processo tecnológico, qualidade ou preço.

\section{RESULTADOS E DISCUSSÃO}

\subsection{Variações no Mercado Internacional de Madeira Serrada}

De acordo com o Quadro 1, no período de 1997 a 1999 o valor das importações norte-americanas apresentou um pequeno aumento de $3,45 \%$, enquanto Japão e Reino Unido reduziram suas importações em 38,69\% e $17,44 \%$, respectivamente. Os demais países importadores reduziram-nas em 6,80\%, levando a uma diminuição do comércio mundial de madeira de 10,29\%.

Diante desse quadro desfavorável foi observada a redução das exportações de madeira em quatro nações, que, junto com o Brasil, responderam por $62,43 \%$ das exportações de madeira no mercado mundial em 1999. No mesmo período, as exportações brasileiras aumentaram em 7,76\%, como pode ser constatado no Quadro 2.

Quadro 1 - Importação mundial de madeira serrada nos anos de 1997 e 1999

Table 1 - World imports of sawn timber, in 1997 and 1999

\begin{tabular}{|l|c|c|c|}
\hline \multirow{2}{*}{ País } & \multicolumn{3}{|c|}{ Valor (US\$ 1.000) } \\
\cline { 2 - 4 } & 1997 & 1999 & Variação (\%) \\
\hline EUA & 7.555 .025 & 7.815 .585 & 3,45 \\
Reino Unido & 1.984 .273 & 1.638 .268 & $-17,44$ \\
Japão & 4.880 .965 & 2.992 .590 & $-38,69$ \\
Outros & 14.000 .477 & 13.048 .271 & $-6,80$ \\
Mundo & 28.420 .740 & 25.494 .714 & $-10,29$ \\
\hline
\end{tabular}

Fonte: FAO (2002).

Quando uma nação exporta produto primário ela perde em divisas a diferença entre o valor da matériaprima exportada e o valor do produto com maior diferenciação que poderia ser comercializado no mercado internacional, além da perda social na alocação de recursos para movimentar a cadeia produtiva que seria demandada para novos processos fabris. Esta face negativa também se mostra no aumento das exportações de madeira serrada. O Brasil deixou de processar um volume maior de madeira em 1999, que poderia gerar produtos mais elaborados.

Quadro 2 - Exportação mundial de madeira serrada nos anos de 1997 e 1999

Table 2 - World export of sawn timber, in 1997 and 1999

\begin{tabular}{|l|c|c|c|c|c|}
\hline \multirow{2}{*}{ País } & \multicolumn{5}{|c|}{ Valor (US\$ 1.000) } \\
\cline { 2 - 6 } & 1997 & Participação (\%) & 1999 & Participação (\%) & Variação (\%) \\
\hline Canadá & 10.036 .292 & 35,31 & 9.193 .297 & 36,06 & $-8,39$ \\
\hline EUA & 2.931 .969 & 10,32 & 2.288 .524 & 8,98 & $-21,94$ \\
\hline Suécia & 2.575 .022 & 9,06 & 2.044 .542 & 8,02 & $-20,60$ \\
\hline Finlândia & 1.697 .398 & 5,97 & 1.519649. & 5,96 & $-10,48$ \\
\hline Brasil & 571.887 & 2,01 & 616.306 & 2,42 & 7,76 \\
\hline Outros & 10.08 .172 & 37,33 & 9.832 .553 & 38,57 & $-7,31$ \\
\hline Mundo & 28.420 .740 & 100,00 & 25.494 .714 & 100,00 & $-10,29$ \\
\hline
\end{tabular}

Fonte: FAO (2002). 
Comparada aos seus concorrentes internacionais, entretanto, a indústria brasileria está fragmentada e descapitalizada, porém a situação do mercado de exportação para o Brasil é positiva e com grande potencial. De acordo com Donnelly (2001), apesar de as exportações de madeira brasileira estarem ainda em desenvolvimento, as tendências predizem um futuro brilhante para este setor. No entanto, o Brasil precisa desenvolver uma base industrial forte capaz de produzir uma larga escala de produtos de madeira e comercializar efetivamente ambos os produtos no mercado interno e externo.

\subsection{Decomposição das Variações nas Exportações (Modelo Constant Market Share)}

Os resultados apresentam a decomposição da variação das exportações totais de madeira serrada, de 1997 a 1999 em US\$ 1.000,00, em três efeitos: crescimento do comércio mundial, destino e competitividade.

As exportações de madeira serrada do Brasil aumentaram em 7,76\% no período analisado (Quadro 3). O efeito crescimento do comércio mundial $(-137,33 \%)$ indica que se as exportações brasileiras tivessem se comportado de forma proporcional à média mundial elas teriam apresentado uma redução $37,33 \%$ superior ao valor do aumento observado, ou seja, apesar da retração do mercado mundial o Brasil aumentou sua participação na exportação. O efeito competitividade de $121,39 \%$ e o efeito destino de $115,94 \%$ superaram a retração de mercado, proporcionando um aumento das exportações.

Pode-se dizer que o aumento nas exportações de madeira serrada no período 1997/1999 ocorreu em

Quadro 3 - Efeitos de variação das exportações brasileiras de madeira serrada em 1997 e 1999

Table 3 - Effects of variation in the Brazilian exports of sawn timber, in 1997 and 1999

\begin{tabular}{|l|c|c|}
\hline & $\begin{array}{c}\text { Valor } \\
\text { (US\$ 1.000) }\end{array}$ & $\begin{array}{c}\text { Valor } \\
(\%)\end{array}$ \\
\hline Exportações 1997 & $571.887,00$ & \\
\hline Exportações 1999 & $616.306,00$ & \\
\hline Crescimento efetivo & $44.419,00$ & 100,00 \\
\hline Efeitos & & \\
\hline Crescimento comércio mundial & $-60.999,24$ & $-137,33$ \\
\hline Destino & $51.499,22$ & 115,94 \\
\hline Competitividade & $53.919,01$ & 121,39 \\
\hline Variação no Período & & 7,76 \\
\hline
\end{tabular}

R. Árvore, Viçosa-MG, v.27, n.5, p.695-700, 2003 virtude do efeito destino (115,94\%), com o aquecimento dos mercados para os quais o Brasil direcionou a maior parte de suas exportações, e através do efeito competitividade (121,0\%), que possibilitou ao País aproveitar o aquecimento destes mercados e aumentar sua participação nas exportações.

A competitividade brasileira apóia-se principalmente em fatores internos, como custo, sistema produtivo, qualidade do produto e taxa de câmbio. Cabe ressaltar que a taxa de câmbio representa um importante componente endógeno: a desvalorização da moeda nacional diante do dólar intensifica as exportações e, analogamente, dificulta a penetração no mercado internacional quando se apresenta sobrevalorizada, acarretando deslocamento de oferta interna, o que, em função da inelasticidade preço dos produtos primários, gera brusca queda de preço.

Em 1999, a taxa de câmbio mostrou-se flexibilizada em relação a 1997, desvalorizando o real em relação ao dólar, o que impulsionou as exportações de madeira serrada, contribuindo para o efeito endógeno tornar-se favorável. Já as demais nações, exceto a Finlândia, têm o desempenho de suas exportações determinado prioritariamente por fatores exógenos, como o volume de comércio mundial e o aquecimento dos mercados.

Com relação às exportações canadenses, observase no Quadro 4 que elas diminuíram em 8,39\%. Como a variação das exportações é negativa, ao apresentarem sinal positivo os efeitos estão na realidade contribuindo para a variação negativa observada, ou seja, para a redução das exportações, fato que ocorre com os resultados referentes às demais nações, exceto o Brasil. Assim, o efeito crescimento do comércio mundial de $122,57 \%$

Quadro 4 - Efeitos de variação das exportações canadenses de madeira serrada em 1997 e 1999

Table 4 - Effects of variation in the Canadian exports of sawn timber, in 1997 and 1999

\begin{tabular}{|l|c|c|}
\hline & $\begin{array}{c}\text { Valor } \\
\text { (US\$ 1.000) }\end{array}$ & $\begin{array}{c}\text { Valor } \\
(\%)\end{array}$ \\
\hline Exportações 1997 & $10.036 .292,00$ & \\
\hline Exportações 1999 & $9.193 .297,00$ & \\
\hline Crescimento efetivo & $-842.995,00$ & 100,00 \\
\hline Efeitos & & \\
Crescimento comércio mundial & $-1.033 .275,95$ & 122,57 \\
\hline Destino & $560.821,96$ & $-66,53$ \\
Competitividade & $-370.541,56$ & 43,96 \\
\hline Variação no Período & & $-8,39$ \\
\hline
\end{tabular}


indica que se as exportações canadenses tivessem se comportado de forma proporcional à média mundial a redução seria $22,57 \%$ superior à observada. $\mathrm{O}$ efeito competitividade de 43,96\% também contribuiu para a redução das exportações, devendo ser ressaltado que somente o efeito destino de - 66,53 compensou os efeitos anteriores, mas não foi suficiente para evitar a redução das exportações. Nota-se que o efeito favorável às exportações é o efeito destino, que é exógeno, visto que o efeito endógeno é desfavorável.

No Quadro 5 constata-se uma redução das exportações de madeira serrada dos Estados Unidos em $21,94 \%$. O efeito crescimento do comércio mundial de $40 \%$ indica que se a redução das exportações americanas acompanhasse a média mundial elas teriam sido $40 \%$ do valor observado. O efeito destino de $-100,82 \%$ seria capaz de superar a redução das exportações, porém o efeito endógeno da competitividade foi de 160,02\%; como a variação é negativa, significa que sozinho seria capaz de reduzir as exportações norte-americanas em 60,02\% além do observado. $\mathrm{O}$ fator favorável às exportações norteamericanas é exógeno, sendo o efeito destino aquele que indica um aquecimento dos mercados priorizados pelos Estados Unidos.

Nota-se nos valores apresentados no Quadro 6 que as exportações de madeira serrada da Finlândia diminuíram em 10,48\%. O efeito crescimento do comércio mundial de $98,12 \%$ explica praticamente toda a redução das exportações. O efeito competitividade de $-19,40 \%$ foi anulado pelo efeito destino de $21,28 \%$. Observa-se que o efeito endógeno contribui para as exportações, porém foi incapaz de superar os efeitos exógenos desfavoráveis.

O Quadro 7 mostra a redução de 20,60\% nas exportações de madeira serrada da Suécia, no período analisado. $\mathrm{O}$ efeito crescimento do comércio mundial de $44,99 \%$ responde pela maior parte da redução das exportações, o efeito competitividade é causador de 35,03\% das reduções e o efeito destino, de $9,98 \%$, o que indica que tanto fatores exógenos como endógenos contribuíram para redução das exportações.

Finalmente, convém ressaltar que este estudo apresenta a limitação de utilizar como base de análise dois anos (1997 e 1999), o que dificulta as conclusões no que se refere a estabelecer uma tendência. Tal procedimento não foi adotado em função da indisponibilidade dos dados necessários.
Quadro 5 - Efeitos de variação das exportações americanas de madeira serrada 1997 e 1999

Table 5 - Effects of variation in the American exports of sawn timber, in 1997 and 1999

\begin{tabular}{|l|c|c|}
\hline & $\begin{array}{c}\text { Valor } \\
\text { (US\$ 1.000) }\end{array}$ & $\begin{array}{c}\text { Valor } \\
(\%)\end{array}$ \\
\hline Exportações 1997 & $2.931 .969,00$ & \\
\hline Exportações 1999 & $2.288 .524,00$ & \\
\hline Crescimento efetivo & $-643.445,00$ & 100,00 \\
\hline Efeitos & & \\
\hline Crescimento comércio mundial & $-262.564,90$ & 40,81 \\
\hline Destino & $648.739,72$ & $-100,82$ \\
\hline Competitividade & $-1.029 .620,0.00$ & 160,02 \\
\hline Variação no Período & & $-21,94$ \\
\hline
\end{tabular}

Quadro 6 - Efeitos de variação das exportações finlandesas de madeira serrada em 1997 e 1999

Table 6 - Effects of variation in the Finnish exports of sawn timber, in 1997 and 1999

\begin{tabular}{|l|c|c|}
\hline & $\begin{array}{c}\text { Valor } \\
\text { (US\$ 1.000) }\end{array}$ & $\begin{array}{c}\text { Valor } \\
(\%)\end{array}$ \\
\hline Exportações 1997 & $1.697 .398,00$ & \\
\hline Exportações 1999 & $1.519 .492,00$ & \\
\hline Crescimento efetivo & $-177.906,00$ & 100,00 \\
\hline Efeitos & & \\
\hdashline Crescimento comércio mundial & $-174.553,50$ & 98,12 \\
\hline Destino & $-37.865,59$ & 21,28 \\
\hline Competitividade & $34.513,10$ & $-19,40$ \\
\hline Variação no Período & & $-10,48$ \\
\hline
\end{tabular}

Quadro 7 - Efeitos de variação das exportações suecas de madeira serrada em 1997 e 1999

Table 7 - Effects of variation in the Swedish exports of sawn timber, in 1997 and 1999

\begin{tabular}{|l|c|c|}
\hline & $\begin{array}{c}\text { Valor } \\
\text { (US\$ 1.000) }\end{array}$ & $\begin{array}{c}\text { Valor } \\
(\%)\end{array}$ \\
\hline Exportações 1997 & $2.575 .022,00$ & \\
\hline Exportações 1999 & $2.044 .542,00$ & \\
\hline Crescimento efetivo & $-530.480,00$ & 100,00 \\
\hline Efeitos & & \\
\hline Crescimento comércio mundial & $-238.669,46$ & 44,99 \\
\hline Destino & $-105.978,72$ & 19,98 \\
\hline Competitividade & $-185.831,82$ & 35,03 \\
\hline Variação no Período & & $-20,60$ \\
\hline
\end{tabular}

R. Árvore, Viçosa-MG, v.27, n.5, p.695-700, 2003 
NOCE, R. etal.

Outro ponto desfavorável é que a metodologia empregada não permite desmembrar o efeito da taxa de câmbio, embora esta seja entendida como um importante componente do efeito endógeno de qualquer nação. Sugere-se, portanto, a realização de estudos futuros, utilizando para comparação valores médios de triênios como a média de 1993, 1994 e 1995, comparada à média de 1998, 1999 e 2000, minimizando, desta forma, os efeitos de curto prazo.

\section{CONCLUSÕES}

De acordo com os resultados obtidos, para as condições em que foi desenvolvido este estudo, concluise que todas as cinco nações analisadas, Brasil, Canadá, Estados Unidos, Suécia e Finlândia, sofreram uma pressão exógena desfavorável à exportação de madeira serrada no período de 1997 a 1999, representada pela redução do comércio mundial.

Apesar da redução observada no valor das exportações, dois países (Canadá e Estados Unidos) apresentaram efeito exógeno favorável. O efeito destino das exportações canadenses e norte-americanas reduziu a queda dos valores exportados.

Apenas dois países apresentaram efeitos endógenos favoráveis às exportações (Brasil e Finlândia), mas apenas o Brasil apresentou uma combinação de efeitos exógenos e principalmente endógenos suficientemente relevante para superar o efeito desfavorável de crescimento do comércio mundial.

O Brasil apresentou-se competitivo, aumentando suas exportações, devendo ser ressaltado que a competitividade brasileira apóia-se principalmente em fatores internos, como custo, sistema produtivo, qualidade do produto e taxa de câmbio.

\section{REFERÊNCIAS BIBLIOGRÁFICAS}

ANGELO, H.; HOSOKAWA, T. R.; BERGER, R. O Brasil no mercado internacional de madeiras tropicais. Revista Árvore, v. 22, n. 4, p. 483-494, 1998.

ANGELO, H. et al. Competitividade da madeira tropical brasileira no mercado internacional. Revista Árvore, v. 24, n. 2, p. 123-126, 2000.

BANCO NACIONAL DE DESENVOLVIMENTO BNDES. Produtos florestais - panorama 1980/1992. Disponível em: <www.bndes.gov.br/conhecimento/relato/ rel4cor.pdf >. Acesso em: 15 julho 2002.

DONNELLY, R. H. Mercado - alternativas de mercado externo para produtos de madeira no Brasil. Revista da Madeira, v. 11, n. 60, p. 10-18, 2001.

FOOD AND AGRICULTURE ORGANIZATION OF THE UNITED NATIONS - FAO. Forestry trade flow (Indicative Raw Data). Disponível em: <http:// apps2.fao.org/TradeFlow/Fytf_Q-e.htm>. Acesso em: 15 julho 2002 .

GONÇALVES, R. Competitividade internacional, vantagem comparativa e empresas multinacionais: o caso das exportações brasileiras de manufaturados. Pesquisa e Planejamento Econômico, v. 17, n. 2, p. 411-436, 1987.

HORTA, M. H. T. T. Fontes de crescimento das exportações brasileiras na década de 70. Pesquisa e Planejamento Econômico, v. 13, n. 2, p. 507-542, 1993.

MEDEIROS, V. X.; FONTES, R. M. Competitividade das exportações brasileiras de celulose no mercado internacional. Revista Brasileira de Economia e Sociologia Rural, v. 32, n. 2, p. 105-121, 1994.

RICHARDSON, D. Constant-market-shares analysis of export growth. Journal of International Economics, v. 1, p. 227-239, 1971. 